\title{
Thanatophoric dysplasia
}

INSERM

\section{Source}

INSERM. (1999). Orphanet: an online rare disease and orphan drug data base.

Thanatophoric dysplasia. ORPHA:2655

Thanatophoric dysplasia (TD) is a severe and generally lethal skeletal dysplasia

presenting in the prenatal period and characterized by micromelia, macrocephaly, narrow thorax, and distinctive facial features. It includes TD, type 1 (TD1) and TD, type 2 (TD2) (see these terms), that can be differentiated from each other by femur and skull shape. 